\title{
Tulane
}

Tulane Economics Working Paper Series

\section{Using Behavioral Economics in Public Economics}

\author{
James Alm \\ Department of Economics \\ Tulane University \\ jalm@tulane.edu
}

\author{
Steven M. Sheffrin \\ Department of Economics \\ Tulane University \\ smsheffrin@tulane.edu
}

Working Paper 1617

December 2016

\begin{abstract}
This paper reviews the methodology of "behavioral economics", and relates these methods to some specific and recent applications.
\end{abstract}

Keywords: Behavioral economics, public economics.

JEL codes: H3, D03 


\title{
Using Behavioral Economics in Public Economics
}

James Alm (jalm@tulane.edu)

Steven M. Sheffrin (smsheffrin@tulane.edu )

\begin{abstract}
This paper reviews the methodology of "behavioral economics", and relates these methods to some specific and recent applications.
\end{abstract}

Keywords: Behavioral economics, public economics.

JEL Classifications: H3, D03.

Most approaches to analyzing behavior have traditionally been based on variants of the standard economic model of behavior, in which an individual is assumed to be a fully rational, self-controlled, and maximizing decision-maker. However, it is increasingly recognized that individuals do not always behave in ways that are consistent with this standard model.

"Behavioral economics" is a catch-all term that has been used to describe this development. Behavioral economics can be loosely defined as the application of methods and evidence from other social sciences like sociology, anthropology, and, especially, psychology to economics, and recent applications expand beyond the social sciences to "hard" sciences like neuroscience. At its core is the belief that increasing the realism with which individual behavior is seen will improve the ability to predict behavior and to devise policies. Its influence in economics has increased enormously in significance in the last two decades, transforming the ways in which economists think about individual behavior. Its influence in public economics has been quite strong, in such areas as compliance, savings incentives, tax incidence, time consistent policies, and social 
insurance, enough so that "behavioral public economics", while a relatively new intellectual movement, is now firmly established in the academic discipline of public economics.

The papers in this special issue of Public Finance Review represent some of the most recent and the most exciting research now being conducted under this broad rubric. Here we want to step back and look at the elements of behavioral public economics, its origins, and the role that it can play in deepening our understanding of fiscal institutions.

The standard neoclassical economic model of human behavior is based on several main assumptions: individuals are rational, they have unlimited willpower, and they are purely selfinterested. While these assumptions may be a useful starting point for the analysis of individual behavior, there is increasing evidence that they are inaccurate and unrealistic depictions of many, perhaps most, individuals. Indeed, there is growing acceptance that, contrary to the standard neoclassical approach:

- Individuals are affected by the ways in which choices are "framed" (e.g., "reference points", gains versus losses, "loss aversion", "risk-seeking behavior", "status quo bias")

- they face limits on their ability to compute (e.g., "bounded rationality", "mental accounting")

- they systematically misperceive, or do not perceive at all, the true costs of actions (e.g., "fiscal illusion", "saliency", "overweighting" of probabilities)

- they face limits on their "self-control" (e.g., "hyperbolic discounting", Christmas savings clubs, automatic enrollment programs)

- they are motivated not simply by self-interest, but also by notions of fairness, altruism, reciprocity, empathy, sympathy, trust, guilt, shame, morality, alienation, patriotism, social customs, social norms, and many other objectives, and

- they are influenced by the social context in which they inhabit, and the process by which decisions are made.

These so-called "deviations" can be classified into three broad areas: non-standard preferences (like other-regarding preferences), imperfect optimization (stemming from, say, limited computation abilities), and bounded self-control (as demonstrated by hyperbolic discounting). 
In short, individuals are not always the rational, outcome-oriented, self-controlled, selfish, and egoistic consumers envisioned by much of the standard theory. Behavioral economics broadly, and behavioral public economics specifically, use these deviations from the standard assumptions as the starting point for a more realistic view on how individuals make choices. Indeed, behavioral public economics opens up a new justification for government intervention in markets (beyond the traditional one based on market failures): when individuals do not optimize even in otherwise well-functioning markets, there may be welfare gains from government actions that help improve individual choices.

The relevance of behavioral insights has long been part of economics, including the works of many of the most prominent economists, from Adam Smith's The Theory of Moral Sentiments (1759), to Francis Edgeworth's Mathematical Psychics (1881), to Amilcare Puviani's Teoria Della Illusione Finanziaria (or The Theory of Fiscal Illusion) (1903), to Irving Fisher's The Money Illusion (1928), and to John Maynard Keynes' The General Theory of Employment, Interest, and Money (1936). Even in the last sixty years or so, economists like Herbert Simon (Administrative Behavior, 1947), George Katona (Psychological Analysis of Economic Behavior, 1951), and Tibor Scitovsky (The Joyless Economy: The Psychology of Human Satisfaction, 1976) have incorporated, and indeed emphasized, the importance of psychology in individual decision-making.

Even so, behavioral public economics as a distinct and well-defined sub-field of public economics is a relatively recent development. Its origins can best be understood by contrasting its approach with what was the standard for public economics, the optimal taxation literature, which first emerged in the 1970 s and reached its full flower in the following decades. Rooted in sophisticated microeconomic foundations of neoclassical economics, the pioneering work of 
economists such as Peter Diamond, James Mirrlees, Anthony Atkinson, Joseph Stiglitz, and, more recently, Louis Kaplow, examined the contours of optimal commodity taxation and optimal income taxation. They derived a series of policy recommendations whose foundations were closely tied to traditional welfare economics. In all their models, they used the standard tools of microeconomics, with a focus on constrained optimization in carefully defined second-best situations. Intellectually, the optimal taxation literature represented a major advance over earlier work in applied welfare economics. It was firmly grounded in neoclassical economics, and its rigor was unquestioned, and its generality provided at least some guidance to policy makers. For example, its results helped support policies that reduced top marginal tax rates on income, that shifted away taxation of intermediate goods, and that taxed more heavily inelastically supplied or demanded activities. Under some especially restrictive assumptions, it also provided support for consumption taxation over income taxation.

However, all of this formalism came at a steep price. Traditionally, public economics had both theoretical and empirical components, and the empirical components were not so fully in the rationality camp. Consider these few examples from empirical analyses, all with much empirical support but all viewed as "anomalous" cases inconsistent with fully rational behavior. In local public finance, the well-known "flypaper effect" suggested that funds would stick to where they originally allocated and not be optimally spread across alternative public sector uses. The "debt illusion" theory of James Buchanan was built on the premise that individuals did not really perceive debt as future taxation in contrast to the hyper-rational doctrine of Ricardian equivalence. On the tax side of the ledger, there is a deep and long-standing research tradition exploring the non-cognitive aspects of tax compliance. As noted earlier, even going back to the classical economists, there was interest in psychological mechanisms. For example, Adam Smith 
noted that people often cared more about the certainty about taxation than its level, an insight that has proven true in many studies of property tax revolts.

Practical empirical and applied work in public economics thus differed from the theoretical work that had so much prominence in the profession. Empirical researchers often paid lip service to the theoretical results, but they pursued their own agenda. Theoretical work itself failed to continue to advance without meaningful engagement from empirical researchers. With this disconnect, something eventually had to change.

It is into this somewhat schizophrenic world that behavioral public economics has recently emerged. What has been the impetus for the recent emergence of this new sub-field?

Probably the immediate precipitating factor was the formalization of behavioral economics as a legitimate sub-field in economics. Based on the work of psychologists Amos Tversky and Daniel Kahneman and the contributions from economists such as Richard Thaler and George Lowenstein, a new field of economics began to emerge that abandoned some traditional rationality principles — for example, expected utility theory_-for alternative theories — such as loss aversion and prospect theory — that were more closely related to empirical, psychological observations. The incorporation of psychologically minded researchers also coincided with a move to integrate experimental research in the laboratory as well as in the field. As this field gained maturity, its application to public economics was inevitable. It allowed a new generation of economic researchers to bring in some of the theories from behavioral economics to public economics as they tested their empirical models. It also stimulated new theoretical work by talented theorists such as Matthew Rabin and David Laibson.

Now a new set of topics was on the public economics research agenda. Do "nudges" affect retirement savings and allocations of investment? Do individuals actually understand and 
respond to the complex marginal rate schedules that are a feature of the modern welfare state? How do people perceive audit risks of non-compliance? Are people too cautious about losses and over-insure for small risks yet fail to buy annuities because they misgauge probabilities? The most famous economists of this generation now work explicitly on behavioral public finance issues, the most prominent including Douglas Bernheim, Raj Chetty, John List, and Emmanuel Saez, among many others. A book of essays edited by Edward McCaffery and Joel Slemrod with the title Behavioral Public Finance was published as recently as 2006.

The papers in this special issue represent some of the most recent work in behavioral public economics. Dina Pomeranz provides a comprehensive overview of the ways in which behavioral notions have been tested in public economics, illustrating these approaches with examples from her own research. John A. List and Anya Samek explore the role of subtle prompts and nudges in inducing students to choose more healthy foods at lunchtime, and they test these ideas in a carefully orchestrated field experiment. Samantha DeMartino, Florence Kondylis, and Astrid Zwager explore another aspect of behavioral economics that has attracted wide attention: Do monetary incentives crowd-out altruistic intentions? Their paper uses outcomes from a pro-environmental program in Brazil to test this hypothesis.

Michael Gideon conducted and analyzed a survey of individuals to test their knowledge of both what they knew about tax rates and whether they could distinguish marginal versus average tax rates. His finding was that individuals have more difficulty understanding marginal tax rates, which is consistent with other empirical work. Stefan Muehlbacher, Barbara Hartl, and Erich Kirchler explore the behavioral economics theory of mental accounting, applying this concept to decisions by new entrepreneurs to pay taxes. In a more formal approach that has roots in the work of Herbert Simon and models of satisficing behavior, Nigar Hashimzade and Gareth 
Myles develop and simulate agent-based models for understanding the interactions of taxpayer compliance and agency audit strategies. This work has great scope to influence our understanding of tax compliance.

We believe that behavioral public economics has now reached the point where it has become an essential part of the public economics dialogue. Behavioral ideas can now be routinely incorporated into public economics research. While these ideas will need to be defended in specific applications, they no longer need a defense simply to incorporate them into ongoing research. New ideas from psychology and behavioral studies can also be incorporated. Much of behavioral economics has been generated through ideas in cognitive psychology, but as Steven Sheffrin argues in Tax Fairness and Folk Justice, there is an undeveloped potential in social psychology. As the work of James Alm and his collaborators has shown, this is a particularly rich area for research in taxpayer compliance.

However, with this opportunity comes a challenge. As the title of Dan Ariely's famous book suggests, what we are looking for is "predictable irrationality." Opening up empirical public economics to broader sources of behavior does not free researchers from testing specific and promising lines of new theories. But to make progress as a field, we need to build on existing behavioral work and focus on the most promising and resilient theory. The challenges here are twofold: to design theories that are realistic but nevertheless tractable enough to generate clear predictions, and then to develop tests of these theories that allow the independent causal effects of policies to be identified and distinguished from other observationally equivalent theories. The papers in this special issue are excellent examples of the types of research that we will need in coming years. 